\title{
Ultrathin Silica Films with a Nanoporous Monolayer
}

\author{
Shunsuke Tanaka, Norikazu Nishiyama, ${ }^{*}$ Yasushi Hayashi, $\dagger$ Yasuyuki Egashira, and Korekazu Ueyama \\ Division of Chemical Engineering, Graduate School of Engineering Science, Osaka University, \\ 1-3 Machikaneyama, Toyonaka, Osaka 560-8531 \\ ${ }^{\dagger}$ Research Laboratories, DENSO CORPORATION, 500-1 Minamiyama, Komenoki-cho, Nisshin, Aichi 470-0111
}

(Received July 13, 2004; CL-040828)

Ultrathin silica films with a monolayer of uniform nanopores were fabricated on a silicon substrate by contacting triblock copolymer films with tetraethoxysilane vapor followed by calcination to remove the copolymer.

Techniques for producing thin films are very important in core industry fields, such as information-communication, energy, and environmental technologies. Silica thin films have been attracting much attention because of their central roles in silicon technology and many other applications. The various methods used for preparing these films include physical vapor deposition (e.g., evaporation, pulsed laser ablation, sputtering) ${ }^{1}$ chemical vapor deposition, ${ }^{2,3}$ oxidation, and sol-gel synthesis. ${ }^{4-6}$

More recently, investigators have succeeded in replicating an ordered mesophase of surfactants into silica substances via the co-assembly of silica precursors and surfactants. ${ }^{7-11}$ Such nanostructured silica thin films are usually prepared by spin coating, dip coating, or epitaxial growth. ${ }^{12-16}$ The removal of the surfactants can be performed through pyrolysis or solvent extraction, converting the silica into a porous form, while retaining the nanostructural features of the surfactant. Although many previous studies have reported on the preparation of these porous silica thin films, few have controlled the number of layers in an ordered structure. It seems to be difficult to fabricate ultrathin silica films with monolayer of nanopores by liquid deposition methods.

We have previously prepared nanoporous silica films by a vapor phase method. ${ }^{17,18}$ In the present study, we have applied this technique to the fabrication of ultrathin silica films with a monolayer of nanopores, and have characterized the products by field emission scanning electron microscope (FE-SEM) and $\mathrm{X}$-ray diffraction (XRD). The detailed synthesis and characterization methods are shown in the references and notes section. ${ }^{19,20}$

Figure 1 shows an FE-SEM image of the cross-section of an ultrathin silica film with a monolayer of nanopores prepared by this vapor phase synthesis. This film was about 15-nm thick, continuous and homogeneous on the silicon substrate. The nanopores were observable from different angles (see Supplemental Information, Figures S1) and seemed to be connected in a planar matrix.

The triblock copolymer film does not have an ordered periodic structure (Figure 2A). A X-ray reflection peak appeared after treating it with tetraethoxysilane (TEOS) vapor (Figure 2B), corresponding to a lattice spacing of $d=15.4 \mathrm{~nm}$. The nanophase transition may occur dynamically via contact between the copolymer film and TEOS vapor. The reflection peak hardly shifted after calcination (Figure 2C). Because the full-width at half-maximum (FWHM) of the peak did not change, we believe the nanostructure remained uniform and did not shrink. The lattice spacing $d$ corresponds to the thickness of a monolayer nanoporous silica film. The FE-SEM image shown as an inset in Figure 2 is a portion of the box in Figure 1, revealing that the pore diameter was about $7.5 \mathrm{~nm}$. The pillar size in the middle and the repeated distance from pillar to pillar were estimated as about 6.0 and $15 \mathrm{~nm}$, respectively.

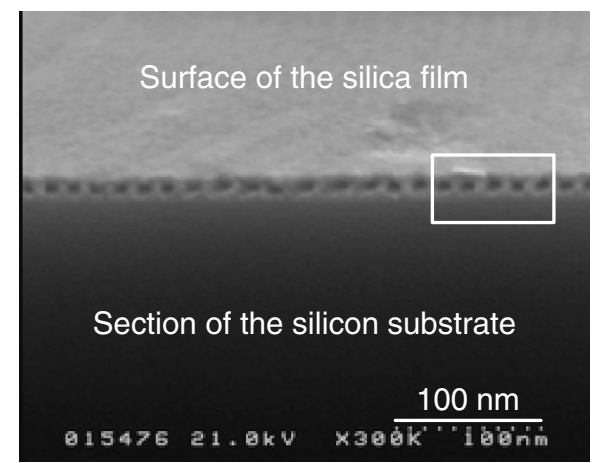

Figure 1. FE-SEM image of the cross-section of an ultrathin silica film with monolayer of uniform nanopores. The film was prepared by vapor phase synthesis.

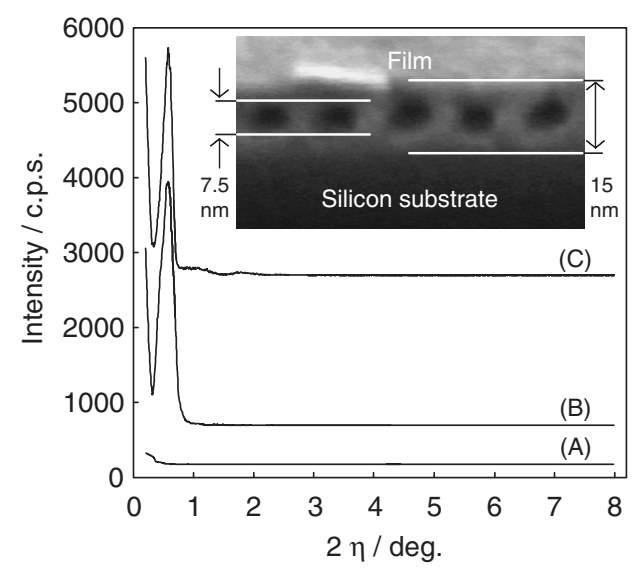

Figure 2. XRD patterns of the monolayered silica film. Trace A is a copolymer film; Trace B shows the copolymer film after treatment with the TEOS vapor (containing the copolymer); Trace $\mathrm{C}$ shows the film after calcination (copolymer-free). The inset is a portion of the box in Figure 1.

The number of layers and the film thickness were very sensitive to the triblock copolymer concentration in the precursor solution. Figure 3 shows the FE-SEM image of the cross-section of a double-layer nanoporous silica film. These films were obtained using a precursor solution with double the concentration 
of the copolymer. The film thickness was about $30 \mathrm{~nm}$, which was double of the monolayer films. On the basis of the FESEM observations (see Supplemental Information, Figures S2), we suggest that the porous structure of this film is the same as that of the monolayer nanoporous films. In the nanoporous films with five and eight layers of nanopores, the nanopores at the film-substrate interface are hemispheric in shape and the silica pillars adhere to the substrate. ${ }^{18}$ In contrast, in the mono- and double-layered films, the silica layer adheres to the substrate. The thin copolymer layer may allow rapid permeation of the TEOS and a high mobility of the silicate-copolymer composite film formed at the film-substrate interface. The thermal conductivity of the double-layer nanoporous silica film (containing the copolymer) was $0.174 \pm 0.007 \mathrm{~W} \mathrm{~m}^{-1} \mathrm{~K}^{-1}$, a level which was lower than that of the bulk silica. The measurements were carried out at $25^{\circ} \mathrm{C}$ in vacuum $(<0.02 \mathrm{~Pa})$. After calcination, the thermal conductivity was decreased by $70 \%(0.125 \pm 0.005$ $\mathrm{W} \mathrm{m}^{-1} \mathrm{~K}^{-1}$ ).

Figure 4 shows the ultrathin silica films obtained by spin coating synthesis. The periodicity of the nanopores was poor although three or four layers of nanopores were observed. It was difficult to fabricate silica films with less than three layers by the spin coating synthesis method.

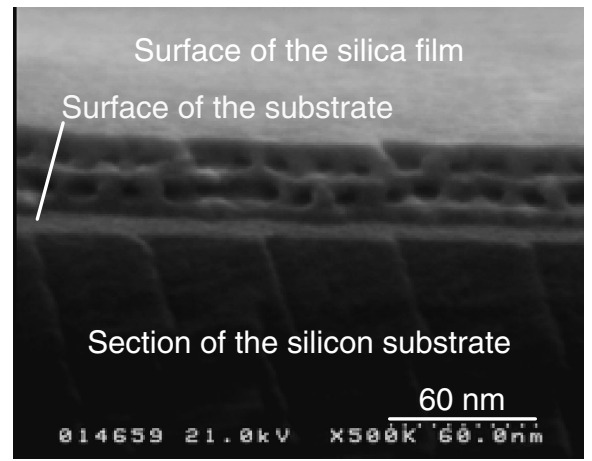

Figure 3. FE-SEM image of the cross-section of an ultrathin silica film with double-layer of nanopores. The film was prepared by vapor phase synthesis.

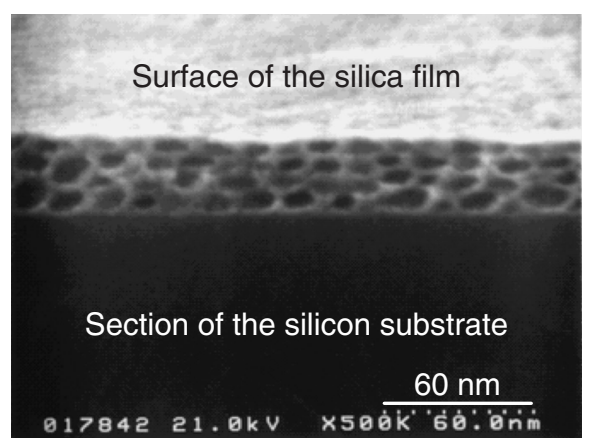

Figure 4. FE-SEM image of the cross-section of an ultrathin silica film with about four layers of nanopores. The film was obtained by spin coating synthesis.

In conclusion, we have successfully fabricated, by vapor phase synthesis, ultrathin silica films with a monolayer of uniform nanopores. We were able to control the number of layers via changes in the triblock copolymer concentration in the precursor solution. Such ultrathin films with a monolayer of nano- pores should perform very well as nanodevices and nanoflasks.

We gratefully acknowledge the assistance of the GHAS laboratory and Mr. M. Kawashima of Osaka University for the FE-SEM measurements.

\section{References and Notes}

1 R. R. Mallik, T. Butler, Jr., W. J. Kulnis, Jr., and B. DeVier, J. Appl. Phys., 73, 2347 (1993).

2 P. A. Bertrand and P. D. Fleischauer, J. Vac. Sci. Technol., B, 1, 832 (1983).

3 S. Yokoyama, D. W. Dong, D. J. DiMaria, and S. K. Lai, J. Appl. Phys., 54, 7058 (1983).

4 C. J. Brinker and G. W. Scherer, "Sol-Gel Science: The Physics and Chemistry of Sol-Gel Processing," Academic Press, New York (1990).

5 D. Avnir, Acc. Chem. Res., 28, 328 (1995).

6 D. Levy, Chem. Mater., 9, 2666 (1997).

7 C. T. Kresge, M. E. Leonowicz, W. J. Roth, J. C. Vartuli, and J. S. Beck, Nature, 359, 710 (1992).

8 S. Inagaki, Y. Fukushima, and K. Kuroda, J. Chem. Soc., Chem. Commun., 1993, 680.

9 J. C. Vartuli, K. D. Schmitt, C. T. Kresge, W. J. Roth, M. E. Leonowicz, S. B. McCullen, S. D. Hellring, J. S. Beck, J. L. Schlenker, D. H. Olson, and E. W. Sheppard, Chem. Mater., 6, 2317 (1994).

10 Q. Huo, R. Leon, P. M. Petroff, and G. D. Stucky, Science, 268, 1324 (1995).

11 D. Zhao, J. Feng, Q. Huo, N. Melosh, G. H. Fredrickson, B. F. Chmelka, and G. D. Stucky, Science, 279, 548 (1998).

12 M. Ogawa, J. Am. Chem. Soc., 116, 7941 (1994).

13 H. Yang, N. Coombs, I. Sokolov, and G. A. Ozin, Nature, 381, 589 (1996).

14 Y. Lu, R. Ganguli, C. A. Drewien, M. T. Anderson, C. J. Brinker, W. Gong, Y. Guo, H. Soyez, B. Dunn, M. H. Huang, and J. I. Zink, Nature, 389, 364 (1997).

15 D. A. Doshi, N. K. Huesing, M. Lu, H. Fan, Y. Lu, K. SimmonsPotter, B. G. Potter, Jr., A. J. Hurd, and C. J. Brinker, Science, 290, 107 (2000).

16 D. A. Doshi, A. Gibaud, V. Goletto, M. Lu, H. Gerung, B. Ocko, S. M. Han, and C. J. Brinker, J. Am. Chem. Soc., 125, 11646 (2003).

17 N. Nishiyama, S. Tanaka, Y. Egashira, Y. Oku, and K. Ueyama, Chem. Mater., 15, 1006 (2003).

18 S. Tanaka, N. Nishiyama, Y. Egashira, Y. Oku, and K. Ueyama, J. Am. Chem. Soc., 126, 4854 (2004).

19 We fabricated ultrathin nanoporous silica films by vapor phase and spin coating synthesis. Vapor phase synthesis: Nonionic amphiphilic triblock copolymer Pluronic F127 $\left(\mathrm{EO}_{106} \mathrm{PO}_{70} \mathrm{EO}_{106}\right)$ was used as a templating agent. A precursor solution of $0.05 \mathrm{~g}$ of Pluronic F127, $9.2 \mathrm{~g}$ of ethanol, and $3.6 \mathrm{~g}$ of deionized water was dropped onto a silicon substrate $(5 \times 5-\mathrm{cm}$ piece $)$, and then the substrate was spun at a rate of up to $4000 \mathrm{rpm}$ for $1 \mathrm{~min}$ using a SPINCOATER $1 \mathrm{H}-\mathrm{DX} 2$ (Mikasa Co.). Next, the triblock copolymer film was placed vertically in a closed vessel $\left(200 \mathrm{~cm}^{3}\right)$ along with a separate, small amount of TEOS and $\mathrm{HCl}(5 \mathrm{~N})$. The vessel was then placed in an oven at $90^{\circ} \mathrm{C}$. Thus, the copolymer film was exposed to a saturated TEOS vapor under autogenous pressure. Removal of the copolymer template from the composite was subsequently carried out by calcination at $400{ }^{\circ} \mathrm{C}$ in air for $5 \mathrm{~h}$ with a heating rate of $1{ }^{\circ} \mathrm{C} / \mathrm{min}$. Spin coating synthesis: A precursor solution of TEOS, Pluronic F127, ethanol, and deionized water was spin-coated on a silicon substrate. The film thickness was controlled by adjustment of the spinning rate and the concentrations in the precursor solution.

20 FE-SEM images were recorded on a Hitachi S-5000L microscope at an acceleration voltage of $21 \mathrm{kV}$. The samples were not coated before the FE-SEM measurements. The ordered structure of the films was investigated with a Philips X' Pert-MPD diffractometer using $\mathrm{Cu} \mathrm{K} \alpha$ radiation with $\lambda=1.5418 \AA$. The copper anode was operated at 40 $\mathrm{kV}$ and $30 \mathrm{~mA}$. The peak evolution was followed in the $\theta / 2 \theta$ Bragg-Brentano scattering geometry, $2 \theta$ varying from 0.2 to 8 degrees, with a step size of 0.01 degree and a time per step of $1.0 \mathrm{~s}$. 